\title{
LETTERS
}

\section{Doubts about first report of krokodil use in Canada}

While the images of necrotic leg ulcers shown in the recent article by Ghazawi and Beecker are certainly graphic, the origin of the ulcers is as murky as the existence of Bigfoot, confirmed only by second-hand oral reports. ${ }^{1}$

Although the authors report that use of krokodil (desomorphine) has been increasing in North America, reports of krokodil harms in North America have not been toxicologically confirmed. ${ }^{2}$ Claims of krokodil use have been circulating since 2013, all without toxicological evidence. Ghazawi and Beecker did not explain how their patient was able to access large quantities of codeine as a precursor and why the patient would favour this toxic homemade brew over more easily accessible heroin.
While a diagnosis of pyoderma granulosum with secondary infection is less glamorous and less worthy of publication, it has the advantage of being more plausible than the first recorded instance of krokodil use in Canada.

\section{Ian V. Mitchell MD}

Emergency physician, Royal Inland

Hospital, Kamloops, BC

Cite as: CMAJ 2019 September 16;191:

E1033. doi: 10.1503/cmaj.73204

\section{References}

1. Ghazawi FM, Beecker J. Necrotic leg ulcers associated with krokodil injection in a 41-year-old man. CMAJ 2019;191:E712.

2. Mullins ME, Schwarz ES. Commentary on "A new drug with a nasty bite: a case of krokodilinduced skin necrosis in an intravenous drug user" [letter]. JAAD Case Rep 2016;2:418.

Competing interests: None declared. 